\title{
Granulometria por difração a laser e sua relação com a faciologia das rochas argilosas da Formação Corumbataí-SP
}

\section{(Grain size distribution by diffraction laser and its relationship with the faciology clay rocks of the Corumbataí Formation-SP)}

\author{
S.R. Christofoletti' ${ }^{1}$ M.M.T.Moreno ${ }^{2}$ \\ ${ }^{1}$ Instituto Florestal, FEENA, Secretaria do Meio Ambiente-SP, Av. Navarro de Andrade s/n, Rio Claro, SP 13500-970 \\ ${ }^{2}$ Instituto de Geociências e Ciências Exatas, Unesp, Rio Claro, SP \\ sergioricardoc@gmail.com,mmoreno@rc.unesp.br
}

\begin{abstract}
Resumo
O presente trabalho analisou a relação entre a distribuição granulométrica por difração a laser e a faciologia dos depósitos argilosos da Formação Corumbataí utilizados como matéria-prima para a indústria de revestimento cerâmico. Foram estudadas 16 seções geológicas de minerações ativas e inativas na região centro-leste do estado de São Paulo. De acordo com os resultados obtidos pela difração a laser em amostras moídas, observou-se que a maior concentração das partículas distribuiu-se no intervalo de $10 \leq \phi \leq 100 \mu \mathrm{m}$ com valor médio de 58,3\% sendo classificadas de siltito grosso a areia muito fina. A segunda maior concentração ocorreu no intervalo $1 \leq \phi \leq 10 \mu \mathrm{m}$ com valor médio de $31,5 \%$ sendo classificadas de siltito grosso. Seguem-se com valores de $4,9 \%$ para o intervalo de $100 \leq \phi \leq 1000 \mu \mathrm{m}$ classificado como siltito fino a médio e de $4,1 \%$ para o intervalo de $0,01 \leq \phi \leq 1 \mu \mathrm{m}$, sendo este último constituído essencialmente por argilominerais. As litofácies identificadas foram: maciça, laminada, intercalada siltosa, intercalada arenosa e alterada. Com o agrupamento das amostras em litofácies, observou-se que a melhor distribuição das partículas para fins de empacotamento ocorreu na litofácies maciça e a pior distribuição na litofácies intercalada arenosa com elevada presença de partículas no intervalo $100 \leq \phi \leq 1000 \mu \mathrm{m}$ com média de $15,4 \%$. Os resultados da análise faciológica aliada à alta concentração de partículas nos intervalos $1 \leq \phi \leq 10$ e $10 \leq \phi \leq 100 \mu \mathrm{m}$ permitem inferir que as matérias-primas estudadas, quando forem submetidas ao processo cerâmico via seco, dependendo do processo de moagem aplicado, poderão resultar em produtos com elevados valores de absorção de água devido à presença predominante das litofácies arenosas e pela seleção de maior tamanho de partículas diminuindo a eficiência do empacotamento durante a prensagem e, consequentemente, dificultando o processo de sinterização. As análises de fácies aliada à análise granulométrica a laser representam importantes ferramentas na previsão do comportamento cerâmico.
\end{abstract}

Palavras-chave: Formação Corumbataí, cerâmica, granulometria, análise de fácies, difração a laser.

\begin{abstract}
This study examined the relationship between the particle size distribution by laser diffraction and facies analysis of clay deposits of the Corumbatai Formation used as raw material for the ceramic tile industry. 16 geological sections of active and inactive mines in the east-central region of São Paulo state were studied. According to the results obtained by laser diffraction of milled samples, the greatest concentration of particles was distributed in the range of $10 \leq \phi \leq 100 \mu m$ with an average of $58.3 \%$, classified as coarse siltstone to very fine sand. The second largest concentration was in the range $1 \leq \phi \leq 10 \mu m$ with an average of $31.5 \%$, classified as coarse siltstone. Followed with values of $4.9 \%$ for the range of $100 \leq \phi \leq 1000 \mu \mathrm{m}$ rated medium fine siltstone, and $4.1 \%$ for the range of $0.01 \leq \phi \leq 1 \mu \mathrm{m}$ essentially composed of clay minerals. The identified lithofacies were: massive, laminated, intercalated silty, intercalated sandy, and altered. By grouping the samples in lithofacies, the best distribution of the particles for packaging purposes occurred in the massive lithofacies and the worst distribution in intercalated sandy lithofacies with high presence of particles in the range $100 \leq \phi \leq 1000 \mu \mathrm{m}$ with average of $15.4 \%$. According to the results of facies analysis coupled with the high concentration of particles in the ranges of $1 \leq \phi \leq 10$ and $10 \leq \phi \leq 100 \mu \mathrm{m}$, it is inferred that the raw materials studied, when applied to the ceramic process, can result in products with high water absorption values due to the predominant presence of sandy lithofacies and the largest particle size selection, which decrease the particle packaging during pressing hindering the sintering process. The facies analyses combined with laser particle size analysis are important tools in predicting the ceramic behavior. Keywords: Corumbataí Formation, ceramic, grain size, facies analysis, laser diffraction.
\end{abstract}

\section{INTRODUÇÃO}

O presente trabalho estudou a relação entre a distribuição granulométrica e a faciologia das rochas sedimentares da Formação Corumbataí. O termo "fácies/ faciologia" representa um conjunto ou estudo das feições caracterizadoras de uma rocha sedimentar e podem ser definidos e separados de outros por: granulometria, 
coloração, geometria deposicional, distribuição de paleocorrentes e pelo conteúdo paleontológico. Estas rochas atualmente representam a principal fonte de matéria-prima para a indústria cerâmica de revestimentos pelo processo via seco. A grande demanda por esta matériaprima faz com que empresas e instituições de pesquisa estudem o comportamento granulométrico desta argila quando submetida a diferentes moagens com o intuito de buscar novos produtos e na melhora dos existentes; entre estes, o maior desafio do Polo de Santa Gertrudes está na produção do porcelanato com qualidade com a matéria-prima da Formação Corumbataí. Alguns trabalhos retratam este assunto, destacando-se [1,2].

Neste trabalho o estudo da análise granulométrica a laser forneceu informações sobre o tamanho e a distribuição das partículas das amostras estudadas, sendo uma ferramenta importante para muitos processos industriais, dentre estes a caracterização de matériasprimas cerâmicas. Alguns trabalhos enfocaram o estudo da análise granulométrica por difração a laser nas argilas da Formação Corumbataí [3-6]. O objetivo do artigo foi analisar a granulometria das matérias-primas da Formação Corumbataí pela técnica de difração a laser buscando entender a relação entre a distribuição das partículas com as características faciológicas descritas nas minerações estudadas nos trabalhos de campo.

\section{METODOLOGIA}

Localização e contexto geológico da área de estudo: a área de estudo está localizada na região centro-leste do estado de São Paulo nos municípios de Porto Ferreira, Tambaú e Santa Rosa do Viterbo. O acesso para o município de Porto Ferreira se dá pela Rodovia Anhanguera (SP 330), seguindo-se depois para os municípios de Tambaú e Santa Rosa do Viterbo pela Rodovia Padre Donizete, SP 332 (Fig. 1). A geologia da região é composta por rochas sedimentares da Bacia do Paraná. A Formação Corumbataí representa uma unidade geológica de idade Permiana composta essencialmente por fácies argilosas e atualmente é a principal fornecedora de matéria-prima para a indústria cerâmica de revestimento.

Trabalhos de campo: os trabalhos de campo tiveram por objetivo identificar as principais litofácies através da análise de fácies em 16 minerações ativas e inativas na área de estudo. A identificação das litofácies baseouse na metodologia elaborada [7] e modificada [8], onde os principais parâmetros avaliados em campo foram: cor, estruturas sedimentares, granulometria e conteúdo paleontológico. Realizou-se também a documentação fotográfica e coleta de amostras das litofácies identificadas que foram encaminhadas para o laboratório.

Análise de laboratório: foi realizada a análise granulométrica por difração a laser e análise química dos óxidos maiores (principais) por ICP-OES/MS nas amostras coletadas. A técnica de análise de tamanho de partículas por difração de laser é um método pelo qual

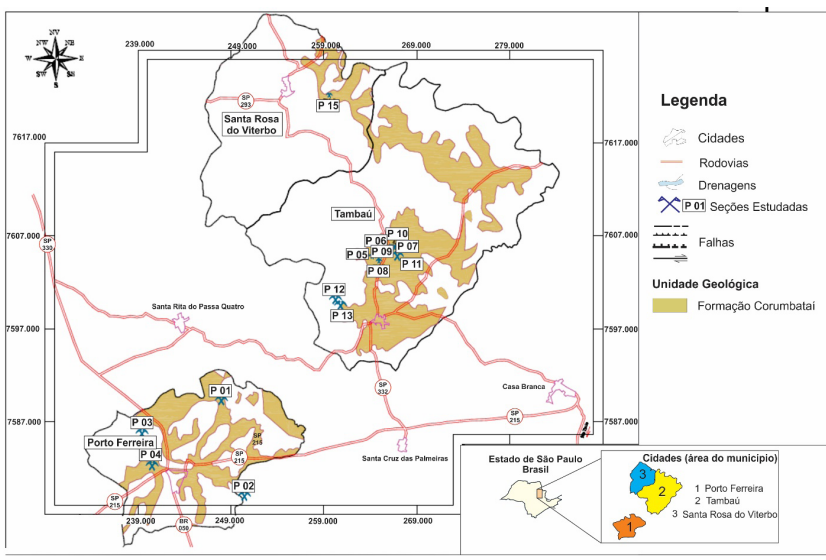

Figura 1: Mapa de localização da área de estudo incluindo as seções estudadas.

[Figure 1: Map of the studied area including the studied sections.]

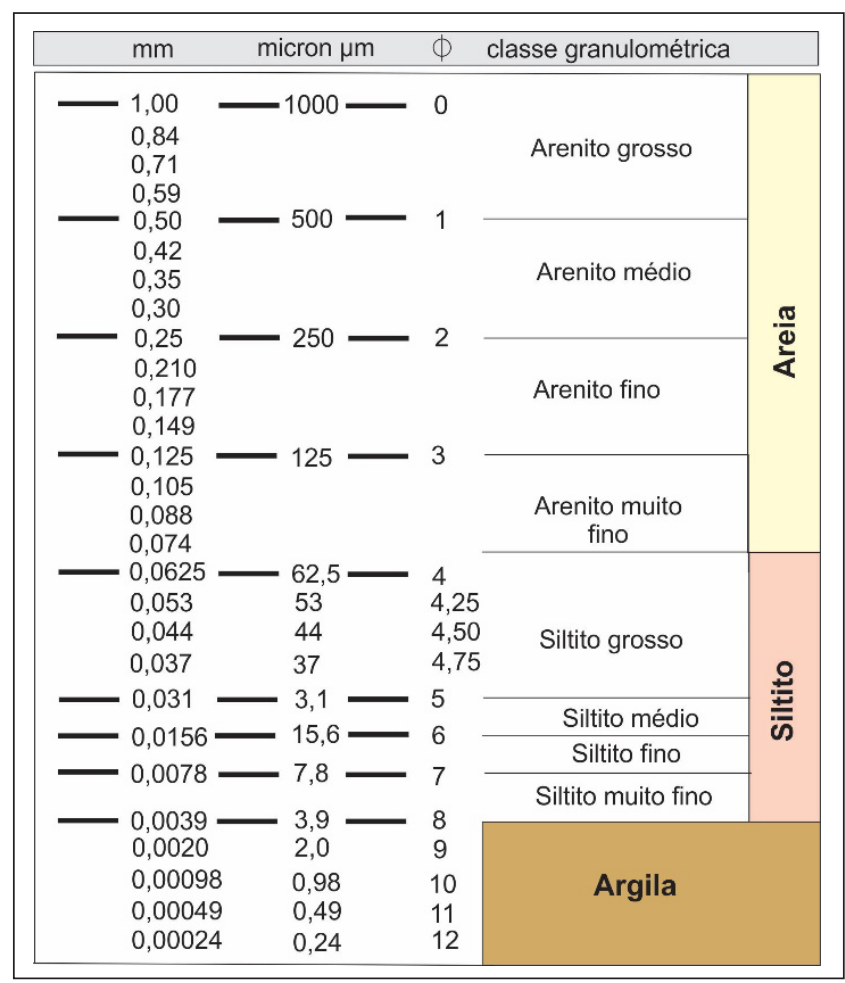

Figura 2: Classificação granulométrica de Udden-Wentworth [8, 9]. [Figure 2: Particle size classification of Udden-Wentworth [8, 9].]

as partículas são dispersas num fluído em movimento causando descontinuidades no fluxo do fluído, que são detectadas por uma luz incidente e correlacionadas com o tamanho de partícula. A maioria dos equipamentos utilizam modelos ópticos em seus softwares de análise baseados em duas teorias: espalhamento de Mie ou na difração de Fraunhofer. Inicialmente as amostras foram moídas em moinho de martelo para laboratório e posteriormente houve a necessidade de se fazer um peneiramento das amostras na malha 45 ABNT de abertura $0,35 \mathrm{~mm}$ para evitar um espalhamento muito alto no espectro de difração, que ocasiona erros de leitura devido a poucas partículas muito grossas. A análise granulométrica foi 
realizada pela técnica de difração de laser no equipamento Mastersizer 2000 da Malvern, na qual uma alíquota da amostra moída foi colocada em uma solução de água e três gotas de hexametafosfato de sódio (10\%), aplicando $15 \mathrm{~s} \mathrm{de}$ ultrassom com deslocamento ultrassônico de 12,5 conforme escala do equipamento. Os gráficos gerados foram obtidos pelo software Mastersize da Malvern v. 5.60. Para análise geoquímica, uma fração das amostras previamente moídas foi encaminhada para a SGS Geosol Laboratórios, onde foram determinados os óxidos dos elementos maiores por ICP-OES/MS. Diversas classificações na literatura levam em conta o tamanho do grão, porém a mais utilizada e difundida na área de geociências, em especial na sedimentologia, é mostrada na Fig. $2[9,10]$.

\section{RESULTADOS}

\section{Análise granulométrica}

Os gráficos das análises granulométricas de frequência por difração a laser (Figs. 3 e 4) mostram a distribuição do tamanho de partícula nas dezesseis seções, onde se observa um comportamento de seleção multimodal em diferentes faixas granulométricas. Para fins comparativos foram agrupadas a partir dos gráficos de frequência acumulada nos intervalos de diâmetro esférico equivalente (D.E.E.) de $0,01 \leq \phi \leq 1,1 \leq \phi \leq 10,10 \leq \phi \leq 100$ e $100 \leq \phi \leq 1000 \mu \mathrm{m}$. As maiores concentrações das partículas encontraram-se nos intervalos de $1 \leq \phi \leq 10$ e $10 \leq \phi \leq 100 \mu \mathrm{m}$ com valores médios que variaram, respectivamente, de $48,23 \%$ até $73,03 \%$ e $20,70 \%$ a $38,26 \%$ (Tabela I), sendo classificadas como siltitos grossos a arenito muito fino (Fig. 2) [9, 10].

De acordo com as Figs. 3 e 4, as seções P1 a P6, P8 a P10 e P12 a P14 apresentaram comportamento semelhante com maior concentração de partículas entre os intervalos de $1 \leq \phi \leq 10$ e $10 \leq \phi \leq 100 \mu \mathrm{m}$. Já as seções P7, P11, P15 e P16 apresentaram um acúmulo maior de partículas no intervalo de $100 \leq \phi \leq 1000 \mu \mathrm{m}$ devido à maior presença dos elementos $\mathrm{K}_{2} \mathrm{O}, \mathrm{SiO}_{2}$ e $\mathrm{CaO}$, indícios de uma maior presença dos minerais microclíneo, calcita e dolomita. A presença destes
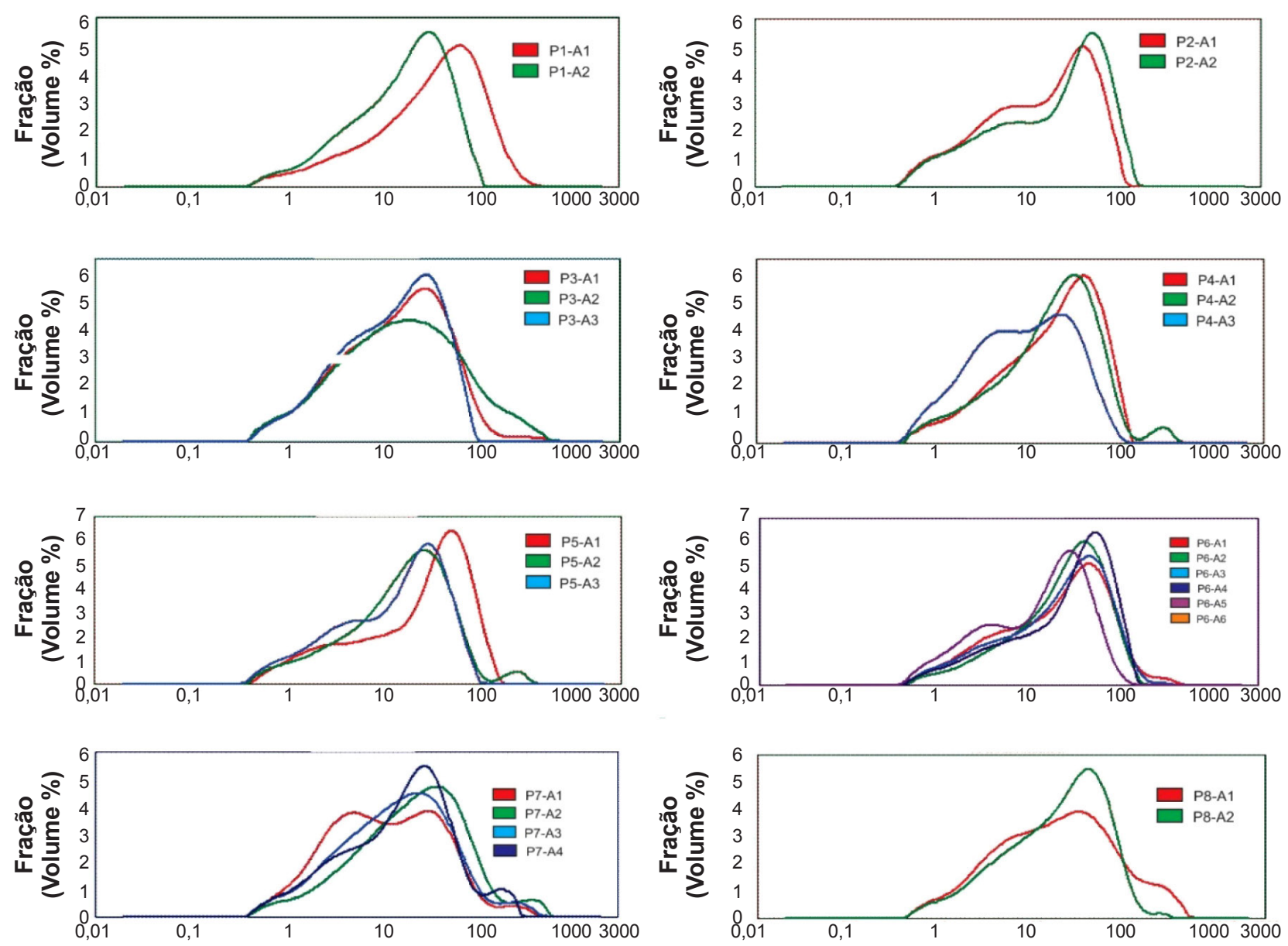

Tamanho da partícula $(\mu \mathrm{m})$

Figura 3: Curvas de distribuição granulométrica obtidas por difração a laser das partículas menores que 0,35 mm de amostras moídas em moinho de martelo das seções estudadas P1 a P8.

[Figure 3: Particle size distribution curves obtained by laser diffraction of particles smaller than $0.35 \mathrm{~mm}$ of the samples milled in hammer mill from the studied sections P1 to P8.] 

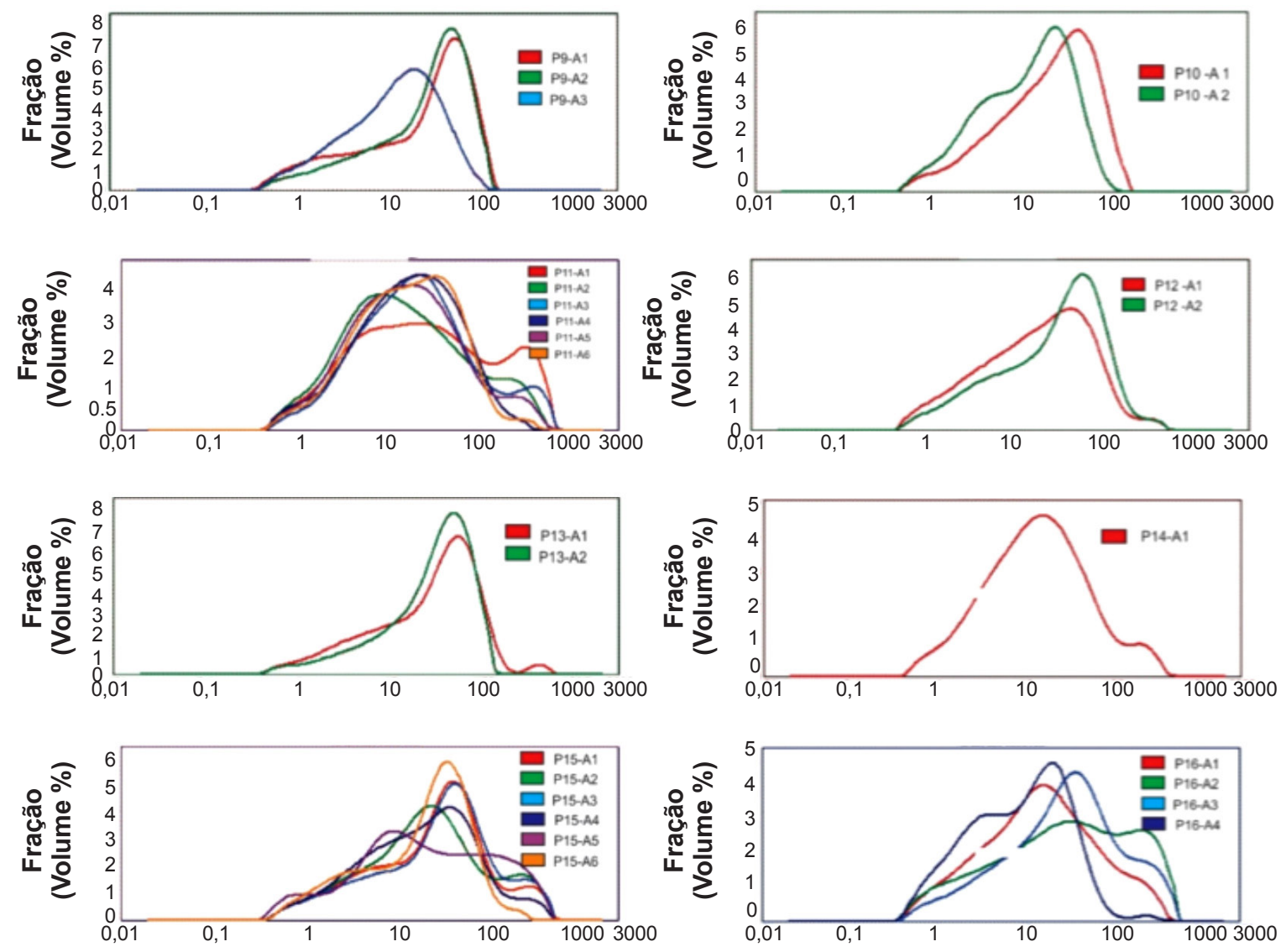

\section{Tamanho da partícula $(\mu \mathrm{m})$}

Figura 4: Curvas de distribuição granulométrica obtidas por difração a laser das partículas menores que 0,35 mm de amostras moídas em moinho de martelo das seções estudadas P9 a P16.

[Figure 4: Particle size distribution curves obtained by laser diffraction of particles smaller than $0.35 \mathrm{~mm}$ of the samples milled in hammer mill from the studied sections P9 to P16.]

minerais foi identificada por difração de raios X [5-11]. No intervalo de $100 \leq \phi \leq 1000 \mu \mathrm{m}$ as amostras das seções P11 e P16 foram as que apresentaram valores médios mais elevados atingindo $10,75 \%$ e $13,62 \%$, tendo apresentado em conjunto a distribuição granulométrica de moagem mais grossa. As amostras das seções P7 e P15 apresentaram distribuições dos grãos menos selecionadas, o que pode facilitar um melhor empacotamento das partículas durante a prensagem.

\section{Descrição das litofácies}

As litofácies identificadas foram: (a) litofácies maciça: formada por siltitos argilosos de cores variadas (cinza escuro/claro, amarelada, vermelho, arroxeada), apresentando estrutura sedimentar maciça, com alguns fragmentos de conchas e escamas fósseis, concreções carbonáticas e ferrosas, diques clásticos arenosos e fraturas pós-deposicionais preenchidas por sílica e carbonato; (b) litofácies laminada: constituída por siltitos de cores variadas (cinza escuro/claro, amarelada, vermelho e arroxeada), apresentando como estrutura sedimentar estratificações plano-paralelas incipientes, dadas pela presença de lâminas de areia fina; também são frequentes fragmentos de conchas, dentes e escamas, além de concreções carbonáticas e ferrosas, diques clásticos arenosos e fraturas pós-deposicionais preenchidas por sílica e carbonato; (c) litofácies intercalada: ocorre ora predominando a areia sobre a argila (litofácies intercalada arenosa - IA) ora predominando a argila sobre a areia (litofácies intercalada siltosa - IS); as camadas de arenito, como as de siltito, apresentam espessuras irregulares centimétricas, podendo ser chamada de ritmito; em algumas seções os níveis de areia apresentam-se enriquecidos em feldspato; (d) litofácies alterada: apresenta-se alterada sem estruturas sedimentares preservadas, coloração branca, vermelha clara e amarelada, granulometria fina a média e marcante na parte superficial dos perfis.

Para uma melhor interpretação dos gráficos de distribuição granulométrica obtidos nas seções, estes foram agrupados de acordo com as litofácies identificadas nos trabalhos de campo utilizando o programa Mastersize 2000 (Fig. 5 e Tabela II), conforme:

i) Litofácies maciça: nas amostras desta litofácies 
Tabela I - Frações de distribuição de tamanho das partículas (\% em volume) das amostras das seções estudadas (M - maciça, L - laminada, IS - intercalada siltosa, IA - intercalada arenosa e A - alterada).

[Table I - Fractions of particle size distribution (vol\%) of the samples of studied sections ( $M$ - massive, L - laminated, IS intercalated silty, IA - intercalated sandy, and A - altered.]

\begin{tabular}{|c|c|c|c|c|c|}
\hline Amostra & $0,01 \leq \phi \leq 1 \mu \mathrm{m}$ & $1 \leq \phi \leq 10 \mu \mathrm{m}$ & $10 \leq \phi \leq 100 \mu \mathrm{m}$ & $100 \leq \phi \leq 1000 \mu \mathrm{m}$ & Litofácies \\
\hline P1-A1 & 3,05 & 31,58 & 65,37 & 0,00 & $\mathrm{~L}$ \\
\hline $\mathrm{P} 1-\mathrm{A} 2$ & 2,47 & 19,73 & 64,51 & 13,29 & IS \\
\hline Média & 2,75 & 25,65 & 64,94 & 6,64 & \\
\hline P2-A1 & 6,57 & 37,84 & 55,59 & 0,00 & $\mathrm{~L}$ \\
\hline P2-A2 & 5,78 & 31,70 & 61,70 & 0,81 & $\mathrm{~L}$ \\
\hline Média & 6,17 & 34,77 & 58,64 & 0,40 & \\
\hline P3-A1 & 4,11 & 36,62 & 57,13 & 2,13 & $\mathrm{~L}$ \\
\hline P3-A2 & 4,17 & 36,83 & 50,93 & 8,07 & $M$ \\
\hline P3-A3 & 3,95 & 39,71 & 56,25 & 0,00 & $\mathrm{~L}$ \\
\hline Média & 4,08 & 37,75 & 54,77 & 3,40 & \\
\hline P4-A1 & 3,18 & 29,00 & 58,56 & 8,47 & $\mathrm{~L}$ \\
\hline P4-A2 & 3,74 & 29,48 & 58,70 & 8,47 & IS \\
\hline $\mathrm{P} 4-\mathrm{A} 3$ & 8,29 & 50,15 & 41,80 & 0,00 & IS \\
\hline Média & 5,07 & 36,21 & 53,02 & 5,64 & \\
\hline P5-A1 & 4,15 & 25,42 & 67,71 & 2,71 & $\mathrm{~L}$ \\
\hline P5-A2 & 4,31 & 30,63 & 62,69 & 2,37 & $\mathrm{~L}$ \\
\hline P5-A3 & 5,45 & 35,53 & 59,01 & 0,00 & $\mathrm{~L}$ \\
\hline Média & 4,64 & 30,53 & 63,13 & 1,69 & \\
\hline P6-A1 & 3,93 & 31,06 & 61,12 & 3,88 & $\mathrm{~L}$ \\
\hline P6-A2 & 2,58 & 25,30 & 70,80 & 1,31 & $\mathrm{~L}$ \\
\hline P6-A3 & 4,00 & 28,21 & 65,23 & 2,55 & $\mathrm{~L}$ \\
\hline P6-A4 & 3,55 & 24,95 & 69,77 & 1,73 & $\mathrm{~L}$ \\
\hline P6-A5 & 6,12 & 37,21 & 56,58 & 0,08 & A \\
\hline Média & 4,03 & 29,35 & 64,70 & 1,91 & \\
\hline P7-A1 & 2,77 & 28,46 & 61,31 & 7,45 & $\mathrm{M}$ \\
\hline P7-A2 & 4,01 & 37,11 & 54,45 & 4,43 & IS \\
\hline P7-A3 & 3,89 & 32,75 & 58,22 & 5,13 & A \\
\hline Média & 3,73 & 36,23 & 55,01 & 5,02 & \\
\hline P8-A1 & 3,78 & 35,42 & 51,10 & 9,69 & IA \\
\hline P8-A2 & 3,34 & 31,76 & 63,34 & 1,65 & A \\
\hline Média & 3,56 & 33,59 & 57,22 & 5,67 & \\
\hline P9-A1 & 5,34 & 25,20 & 67,16 & 2,29 & $\mathrm{~L}$ \\
\hline P9-A2 & 3,17 & 22,02 & 73,23 & 1,57 & $\mathrm{~L}$ \\
\hline P9-A3 & 4,50 & 40,34 & 55,04 & 1,12 & A \\
\hline Média & 4,33 & 29,19 & 65,14 & 1,66 & \\
\hline P10-A1 & 3,18 & 28,65 & 66,96 & 1,20 & $\mathrm{~L}$ \\
\hline P10-A2 & 4,40 & 43,00 & 52,60 & 0,00 & A \\
\hline Média & 3,79 & 35,82 & 59,78 & 0,60 & \\
\hline P11-A1 & 3,13 & 24,77 & 58,8 & 12,79 & IA \\
\hline P11-A2 & 3,01 & 27,04 & 52,74 & 15,93 & IA \\
\hline P11-A3 & 3,25 & 22,14 & 58,21 & 16,96 & IA \\
\hline P11-A4 & 3,09 & 30,80 & 57,04 & 10,00 & M \\
\hline P11-A5 & 5,25 & 30,70 & 42,80 & 5,25 & IA \\
\hline P11-A6 & 3,57 & 27,10 & 64,86 & 3,57 & $\mathrm{~L}$ \\
\hline Média & 3,55 & 27,09 & 55,74 & 10,75 & \\
\hline P12-A1 & 5,21 & 35,63 & 55,63 & 3,52 & M \\
\hline $\mathrm{P} 12-\mathrm{A} 2$ & 3,32 & 26,72 & 65,11 & 4,78 & $\mathrm{~L}$ \\
\hline Média & 4,29 & 31,18 & 60,37 & 4,15 & \\
\hline P13-A1 & 2,69 & 23,39 & 67,95 & 5,96 & $\mathrm{~L}$ \\
\hline P13-A2 & 2,22 & 18,02 & 78,11 & 1,65 & A \\
\hline Média & 2,45 & 20,70 & 73,03 & 3,80 & \\
\hline P14-A1 & 3,68 & 38,18 & 51,49 & 6,65 & $\mathrm{M}$ \\
\hline P15-A1 & 3,54 & 35,47 & 38,06 & 23,38 & IA \\
\hline P15-A2 & 4,48 & 43,16 & 41,12 & 11,24 & M \\
\hline P15-A3 & 2,64 & 33,37 & 52,62 & 11,30 & IA \\
\hline P15-A4 & 4,01 & 37,06 & 55,69 & 3,23 & M \\
\hline P15-A5 & 3,70 & 41,29 & 47,36 & 7,68 & M \\
\hline P15-A6 & 3,13 & 39,24 & 54,72 & 2,91 & M \\
\hline Média & 3,58 & 38,26 & 48,26 & 9,96 & \\
\hline P16-A1 & 4,92 & 35,74 & 49,35 & 9,98 & $M$ \\
\hline P16-A2 & 5,25 & 25,45 & 43,74 & 25,55 & IA \\
\hline P16-A3 & 3,02 & 22,97 & 56,11 & 17,89 & IA \\
\hline P16-A4 & 7,70 & 44,92 & 46,31 & 1,07 & IS \\
\hline Média & 5,22 & 32,27 & 48,87 & 13,62 & \\
\hline
\end{tabular}



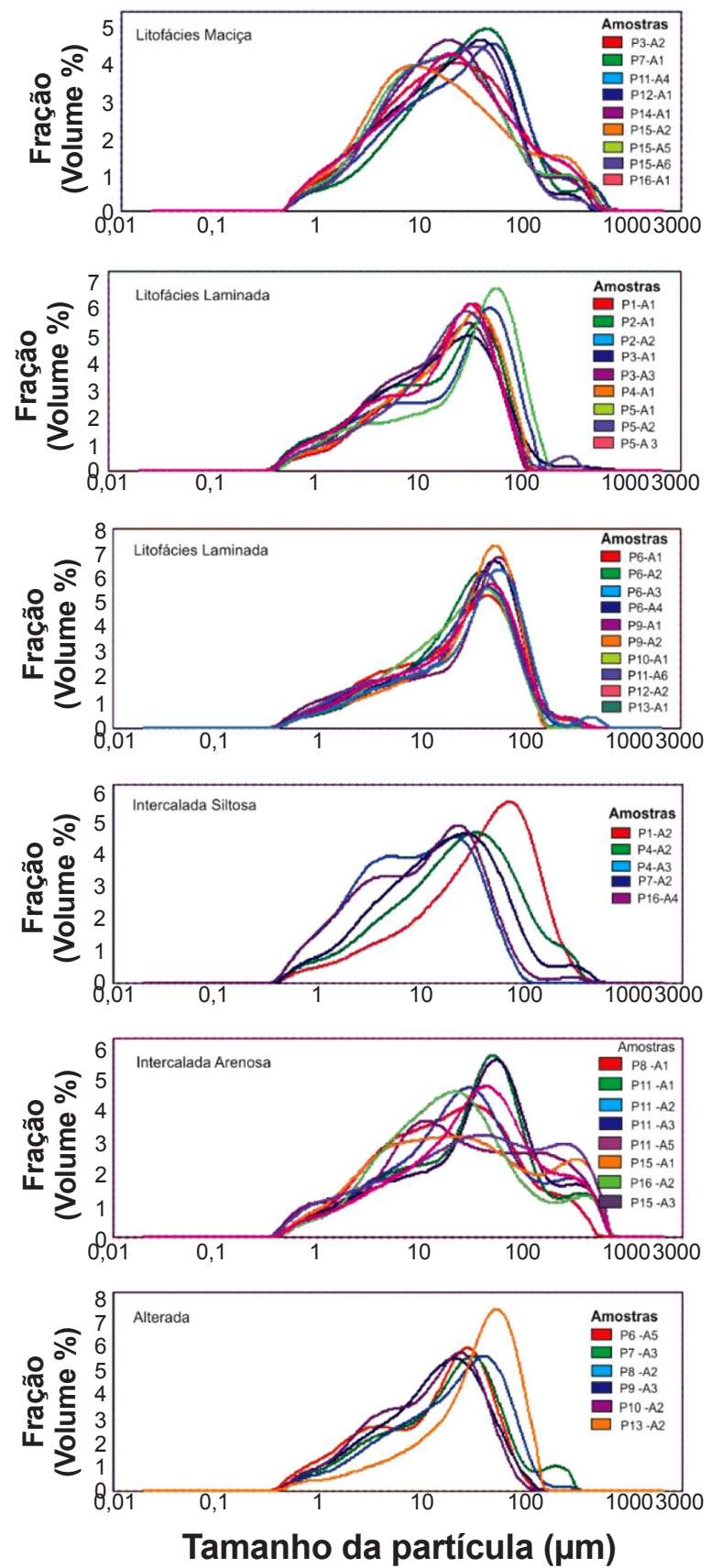

Figura 5: Curvas de distribuição granulométrica agrupadas de acordo com as litofácies.

[Figure 5: Particle size distribution curves grouped according to lithofacies.] observam-se distribuições de tamanho mais abertas e uniformes das partículas. Esta litofácies apresenta-se mais fina em relação às demais com maior presença de argilominerais. Observam-se valores altos de $\mathrm{K}_{2} \mathrm{O}$ em relação aos demais grupos chegando a valores de 7,16\% na amostra P16-A1 (Tabela III). As amostras desta litofácies apresentaram concentrações elevadas para a faixa granulométrica $100 \leq \phi \leq 1000 \mu \mathrm{m}$ com valor médio de $7,5 \%$, provavelmente pela maior contribuição de $\mathrm{K}_{2} \mathrm{O}$ proveniente de feldspato potássico (Tabela III);

ii) Litofácies laminada: as amostras desta litofácies apresentaram concentrações elevadas de partículas entre os intervalos $1 \leq \phi \leq 100 \mu \mathrm{m}$ e baixas concentrações no intervalo de $100 \leq \phi \leq 1000 \mu \mathrm{m}$ com valores médios, respectivamente, de $92,45 \%$ e 2,38\% (Tabelas II e III). Em relação ao $\mathrm{K}_{2} \mathrm{O}$, apresentaram-se com valores mais baixos em relação às amostras da litofácies maciça;

iii) Intercalada siltosa: neste grupo, as distribuições de tamanho das partículas apresentaram-se moderadamente uniformes em relação aos outros com destaque para o intervalo $1 \leq \phi \leq 10 \mu \mathrm{m}$ com valor médio de $36,30 \%$. Estas variações de tamanho das partículas foram apresentadas pelas amostras P16-A4 e P4-A3 mais finas (argilosas), dada pela baixa presença de $\mathrm{SiO}_{2}$ e $\mathrm{K}_{2} \mathrm{O}$ (Tabela III). Já as amostras P4-A2 e P7-A2 apresentaram-se intermediárias e a amostra P1-A2 a mais grossa, com elevado valor de $\mathrm{SiO}_{2}$ de 72,41\%;

iv) Intercalada arenosa: observa-se no agrupamento das amostras desta litofácies uma baixa concentração de partículas no intervalo $10 \leq \phi \leq 100 \mu \mathrm{m}$ em relação aos demais grupos com valor médio de $50,46 \%$ e uma alta concentração de partículas no intervalo $100 \leq \phi \leq 1000 \mu \mathrm{m}$ com valor médio de $15,41 \%$. As amostras, P11-A3, P15-A1, $\mathrm{P} 16-\mathrm{A} 2$ e P16-A3 apresentaram altos valores de $\mathrm{K}_{2} \mathrm{O}$ e $\mathrm{CaO}$ (Tabela III), o que colaborou com a elevada concentração de partículas entre o intervalo $100 \leq \phi \leq 1000 \mu \mathrm{m}$ dificultando o processo de moagem;

v) Litofácies alterada: as amostras deste grupo apresentaram as mais elevadas concentrações de partículas na faixa entre $1 \leq \phi \leq 100 \mu \mathrm{m}$ com valor médio de $94,48 \%$ e as menores na faixa $100 \leq \phi \leq 1000 \mu \mathrm{m}$ com valor médio de $1,59 \%$ (Tabela II). Observa-se neste grupo que a amostra P13-A2 apresentou curva de distribuição granulométrica deslocada para maiores tamanhos de partículas, o que indicou uma maior presença de $\mathrm{SiO}_{2}$ proveniente do mineral quartzo.

Tabela II - Frações médias (\% em volume) em intervalos de tamanho das partículas dos agrupamentos das litofácies após moagem das amostras.

[Table II - Average fractions (vol\%) in particle size ranges of the groups of lithofacies after grinding of the samples.]

\begin{tabular}{cccccc}
\hline Litofácies & $0,01 \leq \phi \leq 1 \mu \mathrm{m}$ & $1 \leq \phi \leq 10 \mu \mathrm{m}$ & $10 \leq \phi \leq 100 \mu \mathrm{m}$ & $1 \leq \phi \leq 100 \mu \mathrm{m}$ & $100 \leq \phi \leq 1000 \mu \mathrm{m}$ \\
\hline Maciça & 3,90 & 36,58 & 52,10 & 88,68 & 7,5 \\
Laminada & 3,99 & 28,35 & 64,10 & 92,45 & 2,38 \\
I-Siltosa & 5,24 & 36,30 & 53,15 & 89,45 & 5,45 \\
I-Arenosa & 3,90 & 28,59 & 50,46 & 79,05 & 15,41 \\
Alterada & 3,87 & 33,84 & 60,64 & 94,48 & 1,59 \\
\hline
\end{tabular}


Tabela III - Elementos maiores (principais) em \% em massa de óxidos.

[Table III - Major elements in wt\% of oxides.]

\begin{tabular}{|c|c|c|c|c|c|c|c|c|c|c|c|}
\hline Amostra & $\mathrm{Al}_{2} \mathrm{O}_{3}$ & $\mathrm{CaO}$ & $\mathrm{TiO}_{2}$ & $\mathrm{SiO}_{2}$ & $\mathrm{Fe}_{2} \mathrm{O}_{3}$ & $\mathrm{~K}_{2} \mathrm{O}$ & $\mathrm{MgO}$ & $\mathrm{MnO}$ & $\mathrm{Na}_{2} \mathrm{O}$ & $\mathrm{P}_{2} \mathrm{O}_{5}$ & LOI \\
\hline P1-A1 & 16,26 & 0,28 & 0,70 & 62,39 & 5,09 & 2,01 & 1,87 & 0,07 & 0,06 & 0,06 & 6,28 \\
\hline P1-A2 & 13,75 & 0,07 & 0,63 & 72,41 & 2,92 & 1,09 & 0,83 & 0,08 & 0,05 & 0,02 & 4,98 \\
\hline Média & 15,00 & 0,17 & 0,66 & 67,40 & 4,00 & 1,55 & 1,35 & 0,07 & 0,05 & 0,04 & 5,63 \\
\hline P2-A1 & 15,51 & 0,02 & 0,63 & 65,65 & 5,92 & 0,99 & 0,45 & 0,02 & 0,03 & 0,03 & 5,87 \\
\hline $\mathrm{P} 2-\mathrm{A} 2$ & 12,28 & 0,01 & 0,55 & 72,84 & 4,41 & 0,82 & 0,67 & 0,02 & 0,04 & 0,01 & 4,53 \\
\hline Média & 13,89 & 0,01 & 0,59 & 69,24 & 5,16 & 0,90 & 0,56 & 0,02 & 0,03 & 0,02 & 5,20 \\
\hline P3-A1 & 13,84 & 0,51 & 0,56 & 70,02 & 4,12 & 2,20 & 1,42 & 0,01 & 0,09 & 0,06 & 5,53 \\
\hline P3-A2 & 12,72 & 0,40 & 0,53 & 68,51 & 4,87 & 3,83 & 1,97 & 0,02 & 0,14 & 0,05 & 4,32 \\
\hline P3-A3 & 13,88 & 0,60 & 0,64 & 70,69 & 2,32 & 2,35 & 2,03 & 0,02 & 0,07 & 0,04 & 5,59 \\
\hline Média & 13,48 & 0,50 & 0,57 & 69,74 & 3,77 & 2,80 & 1,80 & 0,01 & 0,10 & 0,05 & 5,14 \\
\hline P4-A1 & 18,66 & 0,04 & 0,89 & 58,53 & 6,76 & 1,63 & 2,62 & 0,18 & 0,04 & 0,03 & 6,92 \\
\hline P4-A2 & 17,35 & 0,11 & 0,72 & 62,52 & 5,10 & 3,00 & 1,33 & 0,10 & 0,88 & 0,04 & 5,07 \\
\hline P4-A3 & 19,81 & 0,01 & 0,89 & 57,73 & 7,12 & 1,53 & 0,61 & 0,07 & 0,07 & 0,15 & 7,05 \\
\hline Média & 18,60 & 0,05 & 0,83 & 59,60 & 6,33 & 2,00 & 1,52 & 0,11 & 0,33 & 0,07 & 6,34 \\
\hline P5-A1 & 12,69 & 0,17 & 0,44 & 67,07 & 2,87 & 7,94 & 1,46 & 0,03 & 0,39 & 0,04 & 2,04 \\
\hline P5-A2 & 13,89 & 0,17 & 0,56 & 64,03 & 4,15 & 7,98 & 2,15 & 0,06 & 0,19 & 0,02 & 2,84 \\
\hline P5-A3 & 13,72 & 0,12 & 0,53 & 63,61 & 4,78 & 6,55 & 2,28 & 0,18 & 0,17 & $<0,01$ & 3,71 \\
\hline P5-A4 & 16,41 & 0,06 & 0,62 & 64,61 & 5,39 & 1,95 & 1,35 & 0,04 & 0,04 & 0,01 & 5,89 \\
\hline Média & 14,17 & 0,13 & 0,53 & 64,83 & 4,29 & 6,10 & 1,81 & 0,07 & 0,19 & 0,02 & 3,62 \\
\hline P6-A1 & 15,03 & 0,13 & 0,55 & 64,74 & 4,25 & 5,05 & 2,54 & 0,07 & 0,13 & 0,04 & 4,83 \\
\hline P6-A2 & 16,41 & 0,07 & 0,55 & 62,24 & 4,19 & 3,53 & 2,94 & 0,05 & 0,11 & 0,06 & 6,47 \\
\hline P6-A3 & 16,25 & 0,02 & 0,60 & 63,05 & 4,35 & 3,37 & 2,60 & 0,03 & 0,06 & 0,07 & 5,85 \\
\hline P6-A4 & 16,81 & 0,02 & 0,51 & 63,83 & 3,63 & 2,35 & 1,88 & 0,03 & 0,08 & 0,04 & 6,64 \\
\hline P6-A5 & 15,48 & 0,02 & 0,71 & 61,20 & 6,14 & 3,55 & 2,42 & 0,04 & 0,06 & 0,03 & 5,82 \\
\hline Média & 15,99 & 0,05 & 0,58 & 63,01 & 4,51 & 3,57 & 2,47 & 0,04 & 0,08 & 0,04 & 5,92 \\
\hline P7-A1 & 14,83 & 0,38 & 0,58 & 61,20 & 5,25 & 4,76 & 3,04 & 0,02 & 0,11 & 0,03 & 5,17 \\
\hline P7-A2 & 11,92 & 0,83 & 0,35 & 70,37 & 2,62 & 2,42 & 2,61 & 0,04 & 0,25 & 0,04 & 5,83 \\
\hline P7-A3 & 14,56 & 0,43 & 0,58 & 62,93 & 4,64 & 3,35 & 2,83 & 0,08 & 0,09 & 0,09 & 6,01 \\
\hline P7-A4 & 13,44 & 0,20 & 0,53 & 65,30 & 5,96 & 2,06 & 1,79 & 0,02 & 0,07 & 0,08 & 5,09 \\
\hline Média & 13,68 & 0,46 & 0,39 & 64,95 & 4,61 & 3,14 & 2,56 & 0,04 & 0,13 & 0,06 & 5,52 \\
\hline P8-A1 & 13,09 & 0,54 & 0,53 & 64,35 & 4,74 & 4,66 & 2,78 & 0,08 & 0,33 & 0,03 & 4,51 \\
\hline P8-A2 & 14,98 & 0,44 & 0,54 & 64,76 & 4,34 & 2,42 & 2,44 & 0,05 & 0,09 & 0,05 & 6,49 \\
\hline Média & 14,03 & 0,49 & 0,53 & 64,55 & 4,54 & 3,54 & 2,61 & 0,06 & 0,21 & 0,04 & 5,50 \\
\hline P9-A1 & 11,47 & 0,30 & 0,37 & 69,85 & 2,80 & 6,80 & 1,46 & 0,13 & 0,41 & 0,11 & 2,24 \\
\hline P9-A2 & 13,15 & 0,09 & 0,50 & 67,30 & 3,57 & 5,82 & 1,70 & 0,08 & 0,23 & 0,05 & 3,64 \\
\hline P9-A3 & 14,63 & 0,06 & 0,68 & 62,04 & 5,08 & 4,66 & 2,69 & 0,08 & 0,10 & 0,03 & 5,02 \\
\hline Média & 13,08 & 0,15 & 0,52 & 66,40 & 3,81 & 5,76 & 1,95 & 0,10 & 0,24 & 0,06 & 3,63 \\
\hline P10-A1 & 13,55 & 0,41 & 0,51 & 66,27 & 3,51 & 2,8 & 2,63 & 0,05 & 0,08 & 0,06 & 5,73 \\
\hline $\mathrm{P} 10-\mathrm{A} 2$ & 14,09 & 0,08 & 0,66 & 63,68 & 5,57 & 3,39 & 2,61 & 0,05 & 0,05 & 0,04 & 5,34 \\
\hline Média & 13,82 & 0,24 & 0,58 & 64,97 & 4,54 & 3,09 & 2,62 & 0,05 & 0,06 & 0,05 & 5,53 \\
\hline P11-A1 & 11,28 & 2,32 & 0,48 & 65,10 & 3,22 & 5,69 & 2,24 & 0,03 & 1,01 & 0,22 & 3,84 \\
\hline P11-A2 & 9,83 & 8,81 & 0,37 & 51,73 & 3,19 & 5,58 & 4,84 & 0,10 & 0,69 & 0,09 & 12,02 \\
\hline P11-A3 & 12,47 & 1,50 & 0,46 & 65,61 & 3,21 & 7,20 & 2,05 & 0,03 & 0,91 & 0,19 & 3,18 \\
\hline P11-A4 & 12,56 & 0,47 & 0,50 & 64,65 & 4,08 & 6,96 & 2,50 & 0,05 & 0,84 & 0,10 & 2,73 \\
\hline P11-A5 & 3,97 & 21,41 & 0,15 & 49,36 & 1,46 & 2,18 & 1,03 & 0,10 & 0,18 & 0,03 & 18,43 \\
\hline P11-A6 & 13,71 & 0,57 & 0,51 & 64,24 & 3,75 & 8,14 & 2,16 & 0,04 & 0,88 & 0,13 & 2,31 \\
\hline Média & 10,63 & 5,84 & 0,42 & 60,11 & 3,15 & 5,95 & 2,47 & 0,05 & 0,75 & 0,12 & 7,08 \\
\hline P12-A1 & 12,98 & 0,14 & 0,44 & 66,27 & 3,77 & 5,17 & 2,38 & 0,07 & 0,25 & 0,04 & 4,19 \\
\hline P12-A2 & 18,08 & 0,07 & 0,49 & 60,15 & 3,99 & 2,99 & 2,49 & 0,10 & 0,09 & 0,09 & 6,86 \\
\hline Média & 15,53 & 0,10 & 0,46 & 63,21 & 3,88 & 4,08 & 2,43 & 0,08 & 0,17 & 0,06 & 5,52 \\
\hline P13-A1 & 18,65 & 0,03 & 0,54 & 60,83 & 3,89 & 2,30 & 1,62 & 0,02 & 0,09 & 0,04 & 7,20 \\
\hline P13-A2 & 13,69 & 0,02 & 0,46 & 72,94 & 2,29 & 0,89 & 1,14 & 0,02 & 0,02 & 0,10 & 5,23 \\
\hline Média & 16,17 & 0,02 & 0,50 & 66,88 & 3,09 & 1,59 & 1,38 & 0,02 & 0,05 & 0,07 & 6,21 \\
\hline P14-A1 & 15,21 & 0,22 & 0,62 & 64,43 & 4,76 & 2,75 & 1,96 & 0,02 & 0,07 & 0,10 & 5,68 \\
\hline $\mathrm{P} 15-\mathrm{A} 1$ & 13,25 & 0,73 & 0,53 & 69,26 & 4,38 & 2,96 & 2,99 & 0,04 & 0,61 & 0,19 & 3,93 \\
\hline P15-A2 & 14,76 & 0,45 & 0,67 & 62,71 & 5,04 & 3,12 & 3,33 & 0,04 & 0,64 & 0,06 & 4,62 \\
\hline P15-A3 & 13,69 & 2,29 & 0,54 & 62,60 & 4,75 & 2,92 & 3,17 & 0,05 & 0,47 & 1,05 & 4,61 \\
\hline P15-A4 & 12,67 & 0,85 & 0,30 & 69,60 & 3,40 & 1,61 & 2,72 & 0,03 & 0,36 & 0,07 & 5,68 \\
\hline P15-A5 & 14,96 & 0,63 & 0,65 & 62,31 & 6,04 & 3,27 & 3,21 & 0,07 & 0,40 & 0,11 & 4,94 \\
\hline P15-A6 & 14,26 & 0,73 & 0,59 & 66,57 & 4,17 & 2,68 & 2,57 & 0,04 & 0,33 & 0,11 & 5,06 \\
\hline Média & 14,11 & 0,84 & 0,54 & 65,35 & 4,65 & 2,75 & 2,85 & 0,04 & 0,41 & 0,24 & 4,93 \\
\hline P16-A1 & 12,82 & 1,56 & 0,50 & 64,09 & 4,05 & 7,16 & 2,96 & 0,05 & 0,58 & 0,10 & 3,72 \\
\hline $\mathrm{P} 16-\mathrm{A} 2$ & 6,49 & 2,51 & 0,24 & 77,57 & 2,27 & 3,71 & 1,57 & 0,03 & 0,21 & 0,09 & 3,40 \\
\hline P16-A3 & 10,68 & 9,13 & 0,37 & 55,18 & 3,08 & 6,25 & 2,36 & 0,06 & 0,55 & 0,11 & 9,20 \\
\hline P16-A4 & 15,61 & 0,05 & 0,53 & 65,34 & 4,53 & 1,82 & 1,30 & 0,06 & 0,03 & 0,04 & 5,92 \\
\hline Média & 11,40 & 3,31 & 0,46 & 65,54 & 3,48 & 4,73 & 2,04 & 0,05 & 0,34 & 0,08 & 5,56 \\
\hline
\end{tabular}




\section{DISCUSSÃO}

De acordo com os resultados obtidos observou-se que a faciologia associada à deposição, diagênese e alteração intempérica dos sedimentos está relacionada à distribuição granulométrica de argilas moídas e consequentemente ao empacotamento obtido após prensagem contribuindo para a seleção de argilas para composição de uma massa cerâmica e controle das características visadas para um determinado produto. Nas seções estudadas foram identificadas as litofácies maciça, laminada, intercalada siltosa, intercalada arenosa e alterada. A granulometria das seções aumentou em direção ao topo, sendo as litofácies basais mais finas e as litofácies de topo mais arenosas.

De acordo com os gráficos obtidos com os agrupamentos das litofácies, observou-se que as distribuições das partículas variaram muito com as litofácies, apresentandose mais uniforme nas litofácies basais (maciça e laminada), moderadamente uniforme na litofácies intercalada siltosa e uma distribuição menos uniforme (litofácies intercalada arenosa) situada na porção superior. A uniformidade das partículas indica a melhor capacidade de preenchimento/ empacotamento durante a prensagem resultando em melhor desempenho no processo de sinterização. Os formatos das curvas de distribuição granulométrica dos gráficos gerados indicam provavelmente a característica do comportamento cerâmico da matéria-prima, sendo que as litofácies maciça e laminada devem apresentar os resultados mais adequados para uso na indústria de revestimento cerâmico via-seca.

De acordo com os resultados dos trabalhos [5, 6], as litofácies maciça/laminada encontradas nas porções inferiores/basais da Formação Corumbataí resultam em corpos cerâmicos com valores de densidade aparente maiores em relação às litofácies de topo/superiores. Isto decorre por estas amostras apresentarem-se menos alterada pela menor ação dos processos intempéricos e por conter uma maior presença de minerais enriquecidos em potássio (illita), o que favorece a melhor distribuição dos grãos e consequentemente uma sinterização mais eficiente. Já em relação às amostras do topo/superiores, elas apresentam densidade aparente mais baixa evidenciada por uma ação intempérica mais atuante, mais arenosa e concentração maiores de quartzo, carbonato e feldspato do tipo microclíneo e do argilomineral caulinita.

A distribuição das partículas nas amostras analisadas mostrou uma predominância nos intervalos $1 \leq \phi \leq 10 \mu \mathrm{m}$ e $10 \leq \phi \leq 100 \mu \mathrm{m}$ sendo classificadas de siltitos médio/ grossos e arenito muito fino. $\mathrm{O}$ acúmulo de partículas no intervalo $100 \leq \phi \leq 1000 \mu \mathrm{m}$ provavelmente foi oriundo de uma matéria-prima arenosa de difícil moagem com presença elevada de $\mathrm{K}_{2} \mathrm{O}$ e $\mathrm{CaO}$, indícios de conteúdo alto de carbonatos e feldspatos, e o acúmulo de partículas no intervalo $0,01 \leq \phi \leq 1 \mu \mathrm{m}$ indicou a presença elevada de argilominerais.

\section{CONCLUSÕES}

A descrição faciológica aliada à análise granulométrica por difração a laser mostrou-se uma ferramenta importante na previsão do comportamento tecnológico da matéria-prima para a indústria de revestimento cerâmico. A distribuição de tamanho das partículas nas amostras analisadas é condicionada pela formação genética dos depósitos. Quando esta distribuição nos gráficos apresenta-se mais uniforme, isto indica provavelmente um comportamento cerâmico mais adequado, favorecendo o empacotamento e o processo de sinterização, sendo esta distribuição encontrada principalmente nas litofácies maciça e laminada. Já a não uniformidade das partículas, com alta concentração de partículas em determinadas faixas granulométricas, por exemplo, litofácies intercalada arenosa, é advinda de excesso de minerais de difícil desagregação durante a moagem ou excesso de partículas finas, o que dificulta o empacotamento das partículas, prejudicando o processo de prensagem e sinterização da peça quando queimada.

\section{AGRADECIMENTO}

Os autores agradecem a FAPESP, Fundação de Amparo a Pesquisa do Estado de São Paulo, pelo aporte financeiro sob o Processo de $\mathrm{N}^{\circ}$ 2012/24219-9.

\section{REFERÊNCIAS}

[1] F.G. Melchiades, M.T. Daros, F.C. Zanelato, A.O. Boschi, Cerâm. Ind. 17, 4 (2012) 13-21.

[2] F.G. Melchiades, L.R.S. Conserva, S. Nastri, E. Cabral, A.O. Boschi, Cerâm. Ind. 17, 5-6 (2012) 14-21.

[3] R.R. Rocha, A. Zanardo, M.M.T. Moreno, Cerâmica 54, 331 (2008) 332-337.

[4] M.M.T. Moreno, R.R. Rocha, L.H. Hirata, Geomaterials 4 (2014) 11-17.

[5] S.R. Christofoletti, M.M.T. Moreno, Cerâm. Ind. 20, 4 (2015) 24-33.

[6] S.R. Christofoletti, A. Batezelli, M.M.T. Moreno, Geociências 34, 4 (2015) 768-783.

[7] A.D. Miall, Principles of sedimentary basin analysis, Springer-Verlag, New York (1984) 490.

[8] V.A. Campanha, "A arquitetura deposicional da bacia sedimentar de Taubaté, SP, como subsídio à delimitação das zonas de produção mineral", Tese Dr., UNESP, Rio Claro (1994)

[9] C.K. Wentworth, J. Geology 30 (1922) 377-392.

[10] J.A. Udden, Bull. Geol. Soc. Am. 25 (1914) 655-744.

[11] S.R. Christofoletti; M.M.T. Moreno, Cerâmica 61, 360 (2015) 469-476.

(Rec. 09/06/2016, Rev. 22/08/2016, 16/11/2016, Ac. $8 / 11 / 2016)$ 